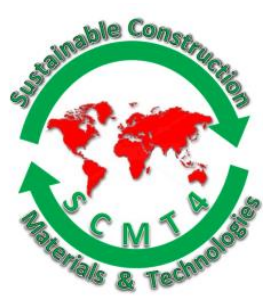

SCMT4

Las Vegas, USA, August 7-11, 2016

\title{
Influence of Intensive Vacuum Mixing on the Compressive Strength of RPC Containing Secondary Slag as Cementitious Material
}

\author{
Romy Suryaningrat Edwin ${ }^{1 \mathrm{a}, 2}$, Elke Gruyaert ${ }^{1 \mathrm{~b}}$, Jeroen Dils ${ }^{1 \mathrm{c}}$, Nele De Belie ${ }^{1 \mathrm{~d}}$ \\ ${ }^{1}$ Magnel Laboratory for Concrete Research, Faculty of Engineering and Architecture, Department of \\ Structural Engineering, Ghent University, Ghent-Belgium. \\ ${ }^{1 a}$ Email: 〈romysuryaningrat.edwin@ugent.be> \\ ${ }^{2}$ Faculty of Engineering, Halu Oleo University, Kendari - Indonesia, ${ }^{1 b}$ Email: <elke.gruyaert@ ugent.be>, \\ ${ }^{1 c}$ Email: <jeroen.dils@ugent.be>, ${ }^{1 d}$ Email: <nele.debelie@ugent.be>
}

\begin{abstract}
This research investigates the influence of intensive vacuum mixing on the compressive strength of reactive powder concrete (RPC) containing secondary slag as cementitious material. The quickly cooled granulated copper slag (QCS) was ground intensively using a planetary ball mill. A low water-to-binder ratio of 0.185 was chosen for the RPC in this study. Various concrete and cement paste samples were produced with increasing copper slag contents from 0 to $20 \mathrm{wt} . \%$ in steps of $5 \mathrm{wt} . \%$. Particle size distribution (PSD) and specific surface area (SSA) of the secondary slag were assessed using laser diffraction and the Blaine permeability test, respectively. The RPC mixes were evaluated on workability, density, and compressive strength. In order to obtain a homogenous mixture and improve the performance of RPC, a high speed mixer with vacuum was applied. The performance of RPC was assessed under vacuum conditions (100 mbar) as a comparison to that of the atmospheric pressure (1013 mbar). The microstructure of RPC was investigated by a scanning electron microscopy (SEM). The pozzolanic activity of QCS was determined by the Frattini test.
\end{abstract}

At 28 days, the strength of RPC with copper slag prepared under 100 mbar was better than the reference (containing no copper slag). In contrast, the strength of RPC containing copper slag mixed under 1013 mbar was lower than the reference. Results also showed that 10\% copper slag replacement for OPC under vacuum conditions gave the highest compressive strength. There is a slight increase in the RPC density under 100 mbar compared to the RPC density under 1013 mbar. The workability of fresh RPC under atmospheric pressure was higher than that of the fresh RPC under vacuum conditions. Assessment of the pozzolanic activity by means of the Frattini test indicates pozzolanic reaction of the secondary slag after curing for 15 days.

\section{INTRODUCTION}

As for all materials, the microstructure of concrete is the key to its performance [Ferraris 2001]. The improvement of microstructure can be achieved by the mixing technology. In addition to the mixing technology, the use of reactive material and curing technology can improve concrete performance. Reactive powder concrete (RPC) is classified as an ultra-high performance concrete (UHPC) (Zenati et al. 2009) which has a compressive strength of $200 \mathrm{MPa}$ when applying heat curing and up to $800 \mathrm{MPa}$ when using steel aggregate (Richard 1995). In the RPC compositions, active powders dominate as the main constituents 
to obtain a relatively dense and homogenous microstructure (Yu et al. 2014, Zang et al. 2008, Yasici et al. 2013). The formation of CSH gel is determined by the hydration process of cement and active powders. However, the high amounts of cement give an adverse effect through the heat of hydration, which creates micro cracks in the concrete. Besides, the production of this concrete implies high costs. In order to solve these problems, the use of industrial by-products as cement replacing material is an option. Typical byproducts that are already widely used are e.g. fly-ash and blast-furnace slag. Copper slag is one of the byproduct materials from the copper smelting. Every year, about 24.6 million tons of copper slag are produced by copper industry throughout the world (Gorai et al. 2003). In Europe, approximately 5.56 million tons of copper slag are generated by the European copper industry (Gorai et al. 2003), and in Belgium, about 132,240 tons of secondary copper slag are produced in the recycling plant annually (FCA 2012, Hagelüken 2006). Since this material needs a large area for landfilling, of which the availability is insufficient, and to avoid problems related to the leaching of heavy metal and other harmful elements, it would be interesting to upgrade these 'waste' products in high-value applications. Moreover, the amount of natural resources is declining due to a large consumption in the cement and concrete production. A possible breakthrough can thus be sought in exploiting by-products within cement and concrete production. This paper presents the influence of vacuum mixing on compressive strength, density, workability, and porosity of RPC containing copper slag as cement replacement. The Frattini test was chosen to assess the pozzolanic activity of secondary copper slag.

\section{EXPERIMENTAL INVESTIGATION}

Materials. The materials used in this study were purchased from a Belgian Company except for the secondary copper slag, which was obtained from a Belgian Recycling Plant. The secondary slag used in this research was quickly cooled granulated copper slag (QCS). This slag was produced by using primary slag from $\mathrm{Cu}$ such as old copper tubes, wires, scraps, cables, alloy coins, plated coins and $\mathrm{Cu}-\mathrm{Fe}$ (shredded) armatures as raw materials to generate copper blister, copper anodes, and copper cathodes for industry and market. Besides copper slag, an undensified silica fume (type 940U, Elkem) was used as SCM. As cement, a CEM I 52.5 N HSR/LA was used throughout all experiments. For all concretes, a quartz flour (type M400, Sibelco) with a $\mathrm{d}_{50}$ of $12 \mu \mathrm{m}$ was used. An overview of the chemical composition of the binders is given in Table 1.

Table 1. Chemical Composition of the Applied Binders Determined by XRF Analysis [wt\%] and Mineralogical Composition of the Cement

\begin{tabular}{|c|c|c|c|c|}
\hline Material & QCS & Cement & Silica fume & Flour (M400) \\
& & & & \\
\hline $\mathrm{CaO}$ & 7.1 & 63.4 & 0.6 & 0.02 \\
$\mathrm{SiO}_{2}$ & 25.9 & 21.5 & 94.2 & 99.5 \\
$\mathrm{Al}_{2} \mathrm{O}_{3}$ & 5.9 & 3.6 & 1.0 & 0.2 \\
$\mathrm{Fe}_{2} \mathrm{O}_{3}$ & 45.5 & 4.2 & 0.5 & 0.03 \\
$\mathrm{MgO}$ & 0.8 & 1.6 & 0.7 & - \\
$\mathrm{Na}_{2} \mathrm{O}$ & 0.8 & 0.2 & 1.0 & - \\
$\mathrm{K}_{2} \mathrm{O}$ & 0.2 & 0.6 & 1.1 & 0.05 \\
$\mathrm{SO}_{3}$ & 0.4 & 2.5 & 0.3 & - \\
& & & & - \\
$\mathrm{C}_{3} \mathrm{~S}$ & - & 57.2 & - & - \\
$\mathrm{C}_{2} \mathrm{~S}$ & - & 18.6 & - & - \\
$\mathrm{C}_{3} \mathrm{~A}$ & - & 2.5 & - & \\
$\mathrm{C}_{4} \mathrm{AF}$ & - & 7.7 & - & \\
& & & & \\
\hline
\end{tabular}


Size reduction processes. Before using the copper slag as cementitious material, QCS was intensively ground using a planetary ball mill. The copper slag was ground at $390 \mathrm{rpm}$ for 6 times 5 minutes. In order to obtain the maximum fineness, this machine was set at grinding direction reversal and pause times of 40 seconds. To avoid agglomeration of the slag upon grinding, a wet method was chosen with addition of a superplasticizer (Sika Viscocrete-3095x; $0.122 \mathrm{wt} \%$ ) to the copper slag in the glass jar. After the grinding process, the particle size distribution (PSD) of copper slag powder was measured by laser diffraction with the size range from $0.1 \mu \mathrm{m}$ to $1000 \mu \mathrm{m}$ ). Wet measurement was chosen to measure the PSD of copper slag due to the re-compaction of this material after the grinding process. The particle size distribution of copper slag and silica fume obtained by laser diffraction is given in Figure 1. To disperse this material, isopropanol was used since it does not react with copper slag. To avoid agglomeration, the copper slag was put in a sonication bath $(5 \mathrm{~min})$ before the measurement. In case of silica fume, distilled water was used as dispersant. In order to obtain well de-agglomerated silica fume, this material was sonicated in two steps. At first, the solution containing silica fume and water was put in an ultrasonic bath for 5 minutes to deagglomerate the particles. After this, $10 \%$ superplasticizer by weight of silica fume was added followed by sonication for 15 minutes prior to measurement. An overview of the parameters used to determine the PSD of the SCMs by laser diffraction can be seen in Table 2.

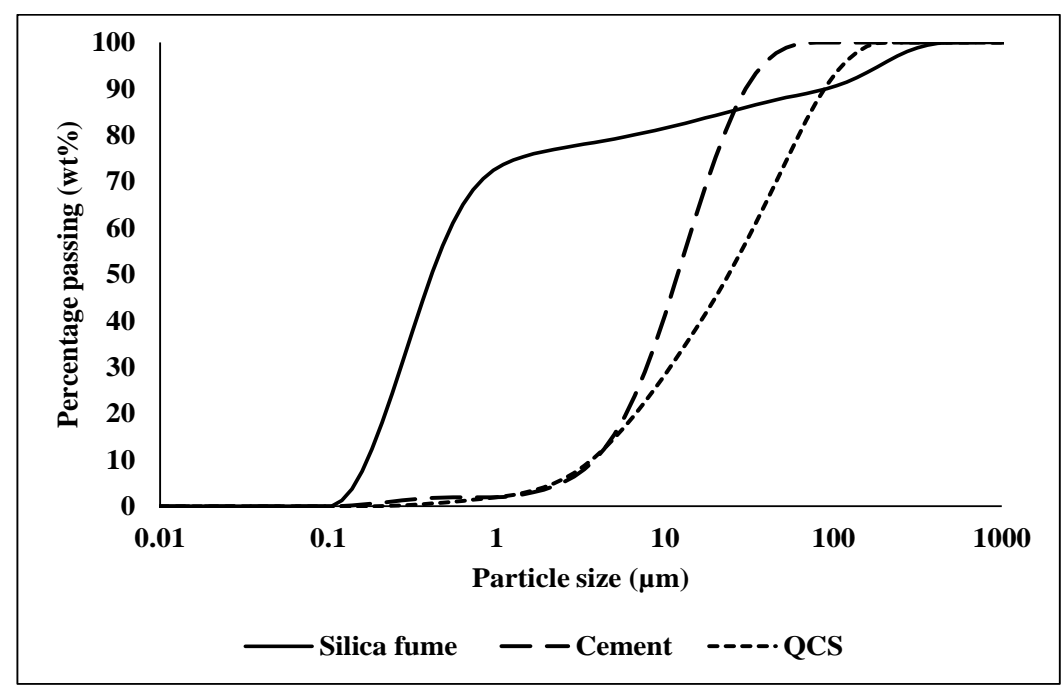

Figure 1. Particle Size Distribution by Laser Diffraction of the Different Binders

In addition to the PSD by laser diffraction, the fineness of the binders was evaluated by their specific surface area (SSA) using the Blaine air permeability test according to NBN EN 196-6:2010. To start, the pycnometer method was used to measure the density of all binders. Both the density and SSA of the binders are presented in Table 3.

Table 2. Overview of the Parameters Applied to Determine the PSD of the Different Binders by Laser Diffraction

\begin{tabular}{|c|c|c|c|}
\hline & QCS & Silica fume & Cement I \\
Optical parameters & & & \\
\hline Refractive index (RI) & 1.731 & 1.530 & 1.731 \\
Absorption coefficient & 0.055 & 0.001 & 0.003 \\
Obscuration [\%] & $10-15$ & $5-10$ & $5-10$ \\
Stirrer rate [rpm] & 1700 & 1500 & 1500 \\
Dispersant RI & 1.390 & 1.390 & 1.390 \\
Sonication times [minutes] & 5 & 20 & 5 \\
\hline
\end{tabular}


Table 3. Density and SSA of the Different Binders

\begin{tabular}{|l|l|l|l|}
\hline Materials & QCS & CEM I & Silica fume \\
\hline Density $\left(\mathrm{g} / \mathrm{cm}^{3}\right)$ & 3.706 & 3.152 & 2.017 \\
\hline SSA $\left(\mathrm{cm}^{2} / \mathrm{g}\right):$ & & & \\
Blaine permeability & 2277 & 4955 & - \\
Laser diffraction & 2150 & 5390 & 56200 \\
\hline
\end{tabular}

Mixtures proportions. Table 4 describes the RPC compositions used in this research. A very low waterto-binder ratio $(\mathrm{w} / \mathrm{b}=0.185)$ was chosen in order to produce ultra high performance concrete (UHPC). To obtain the desired workability, a polycarboxylate ether (Glenium ACE 30 con 35\% S) was used. The concrete was made with copper slag contents varying between 0 and $20 \mathrm{wt} \%$ in steps of $5 \mathrm{wt} \%$.

Table 4. Composition of the RPC Mixtures with Copper Slag

\begin{tabular}{|l|l|l|l|l|l|l|}
\hline \multicolumn{1}{|c|}{ Material } & & Reference & $5 \%$ CS & $10 \%$ CS & $15 \%$ CS & $20 \%$ CS \\
\hline CEM I 52.5 N HS/NA & $(\mathrm{g})$ & 2550 & 2423 & 2295 & 2168 & 2040 \\
Copper slag & $(\mathrm{g})$ & 0 & 127 & 255 & 382 & 510 \\
Silica fume (940 U) & $(\mathrm{g})$ & 800 & 800 & 800 & 800 & 800 \\
Sand M31 & $(\mathrm{g})$ & 3507 & 3507 & 3507 & 3507 & 3507 \\
Flour M400 & $(\mathrm{g})$ & 637 & 637 & 637 & 637 & 637 \\
Glenium ACE & $(\mathrm{g})$ & 99 & 99 & 99 & 99 & 99 \\
Water Total & $(\mathrm{g})$ & 620 & 620 & 620 & 620 & 620 \\
Water Glenium & $(\mathrm{g})$ & 64 & 64 & 64 & 64 & 64 \\
Water Compensated & $(\mathrm{g})$ & 556 & 556 & 556 & 556 & 556 \\
\hline
\end{tabular}

Vacuum mixing. One measure to obtain a void-free mixture is to use an intensive vacuum mixing in which this mixer can remove air content. A void-free mixture contributes to the strength and service life of concrete. In this research, the authors used a planetary vacuum mixing with a capacity of 5 liter. The procedure of mixing is mentioned in Figure 2 [Dils et al. 2013].

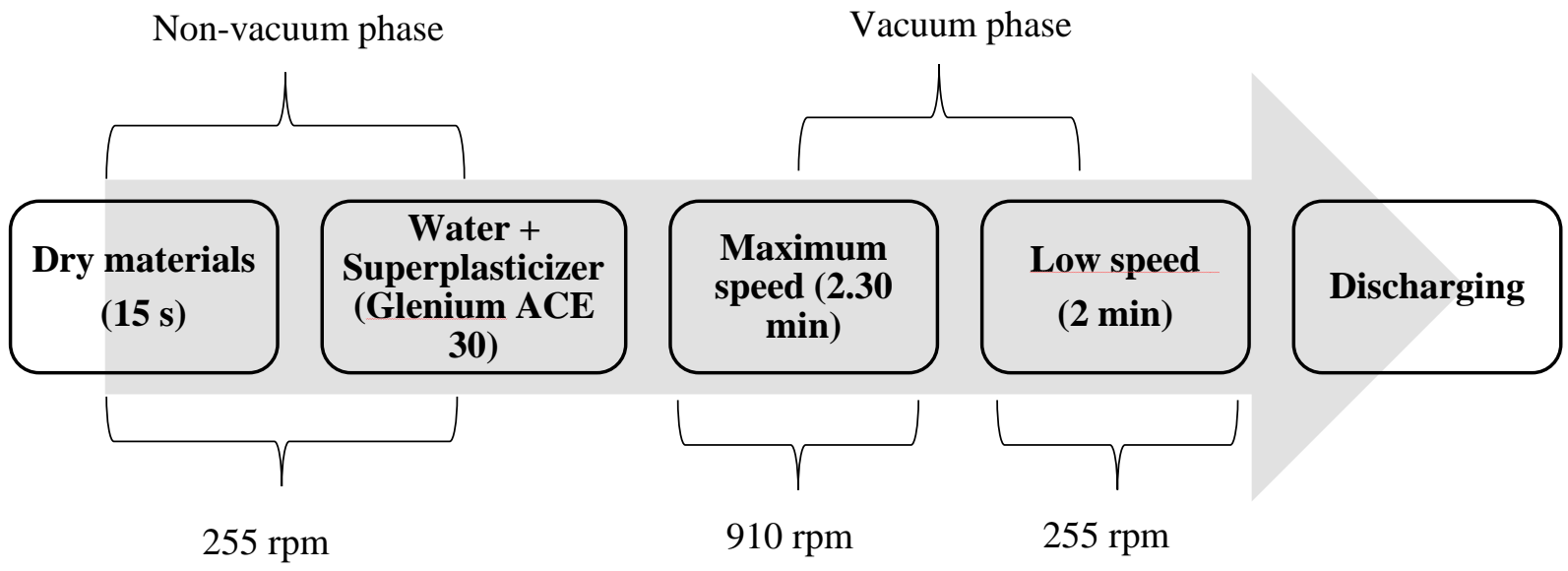

Figure 2. Mixing Procedure

Pozzolanic activity. To evaluate the pozzolanic activity of copper slag, the Frattini test was performed according to NBN EN 196-5. The compositions used in this test were made with an increasing copper slag content from $0 \mathrm{wt} \%$ to $20 \mathrm{wt} \%$ in steps of $5 \mathrm{wt} \%$. After preparation, the samples in sealed polyethylene containers were heated in an oven at $(40 \pm 1){ }^{\circ} \mathrm{C}$ for 8 days and 15 days. After the first period of 8 days, the samples were removed from the oven and then filtrated using double filter paper with pore diameter of 
$2 \mu \mathrm{m}$ in less than 30 seconds to prevent the contamination with carbon dioxide. Afterwards, the filtered solution was first titrated with $0.1 \mathrm{M}$ hydrochloric acid using methyl orange indicator to determine the hydroxyl ion concentration as first step. After adaptation the $\mathrm{pH}$ solution until 12.5, a second titration was performed with $0.03 \mathrm{M}$ EDTA solution using Patton and Reeders indicator to find out the calcium oxide concentration. To assess the pozzolanic reaction degree of copper slag, titration results are plotted in a graph of hydroxyl ion content $\left[\mathrm{OH}^{-}\right]$on the $\mathrm{x}$-axis and calcium ion content $\left[\mathrm{Ca}^{2+}\right]$ on the y-axis. The results indicate pozzolanic activity when they are beneath the lime saturation curve.

\section{RESULTS AND DISCUSSIONS}

Properties of freshly mixed RPC. The workability of RPC was determined by measuring the flow according to NBN EN 1015-3. The flow test of RPC is shown in Figure 3. It is clear that the slump flow of RPC mixed under vacuum of 100 mbar is lower than that of RPC under atmospheric pressure. This result also indicates that the fresh concrete with less air content contributes to decrease the workability. Looking into the literature, opposite effects were obtained by several researchers [Dils et al. 2012; Mazanec and Schiessl 2008; Wille et al. 2011; Zain et al. 1999]. In their research, they concluded that the workability can be improved by decreasing air content.

Figure 3 also describes that the increase of copper slag content in RPC under vacuum condition and atmospheric pressure enhanced the workability of the fresh mortar. This phenomenon can be explained by the fact that copper slag is not a good water absorber. This may thus cause bleeding if a high proportion copper slag material is used. This is a reason for the increase of the workability of RPC with CS.

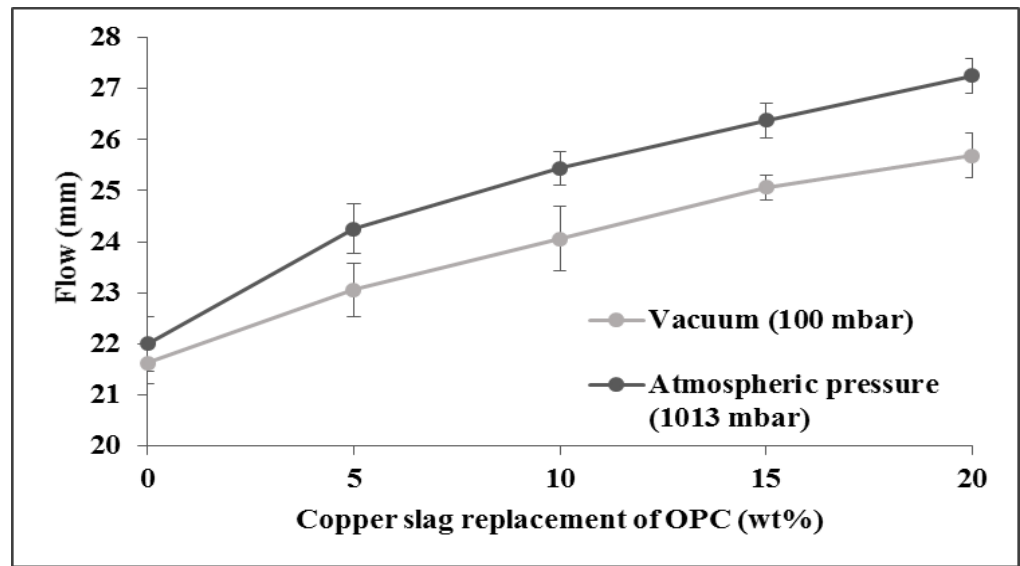

Figure 3. Workability of RPC under Vacuum (100 mbar) and Atmospheric Pressure (1013 mbar) (error bars represent standard errors, the average values represent three replicates)

Compressive strength and density. Figure 4 describes the effect of copper slag replacement on the compressive strength of RPC mixed under vacuum (100 mbar) and atmospheric pressure (1013 mbar) at 7 , 28 , and 56 days. In general, the strength of RPC under vacuum (100 mbar) and atmospheric pressure (1013 mbar) increases with rising copper slag content in RPC mixture. Figure 4(a) shows that the strength of RPC (atmospheric pressure) containing copper slag is lower than the reference for all curing ages. Despite the fact that the strength development of the $15 \%$ CS and 20\% CS was similar or even better than the reference mixture at 28 days, it was lower than the reference at 56 days. From this result, it can be stated that the use of copper slag will have no positive effect on the strength of RPC when mixed in a high speed mixer at atmospheric pressure. The fineness of copper slag used in this study was not similar with the OPC (see Fig 1 and Table 3), which caused less reaction with cement to form calcium silicate hydrates during the hydration process [Edwin et al. 2015]. However, a positive effect on strength of RPC containing copper slag is achieved when applying a vacuum of 100 mbar as seen in Figure 4(b). The results of RPC copper slag were higher than that of the reference mixture for all curing ages. The highest compressive strength 
(158 MPa) was achieved for $10 \%$ copper slag at 56 days of curing, which increased about $7 \%$ compared to the control specimens. Nevertheless, the fact that at early ages the strength of the reference RPC under vacuum (100 mbar) was lower than the reference RPC under atmospheric pressure needs further investigation.

The use of the vacuum technique for the RPC mixture seems to enhance compressive strength at 56 days compared to the RPC without vacuum as seen in Figure 5. This improvement is mainly caused by two reasons: (1) The vacuum mixing reduces the air content in the mixture and creates less porosity in the RPC; (2) The physical properties of the copper slag play a role to increase the compressive strength. The improvement of the cohesion of the concrete matrix is due to the angular sharp edges of the copper slag. The effects regarding the porosity are discussed later in this paper.

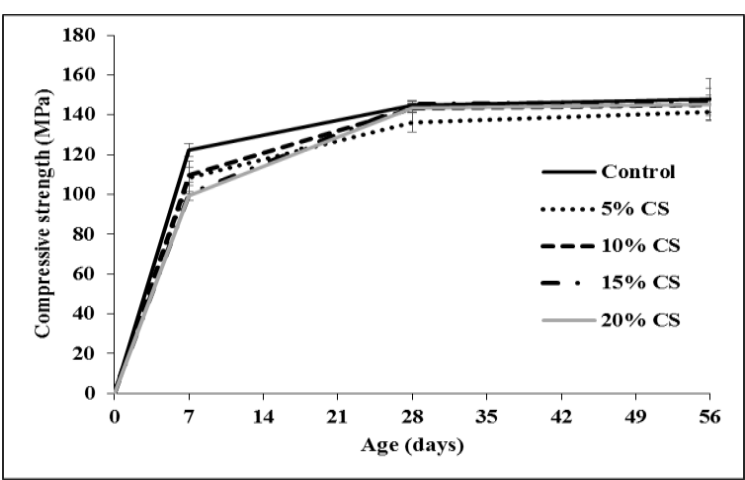

(a) Atmospheric Pressure (1013 mbar)

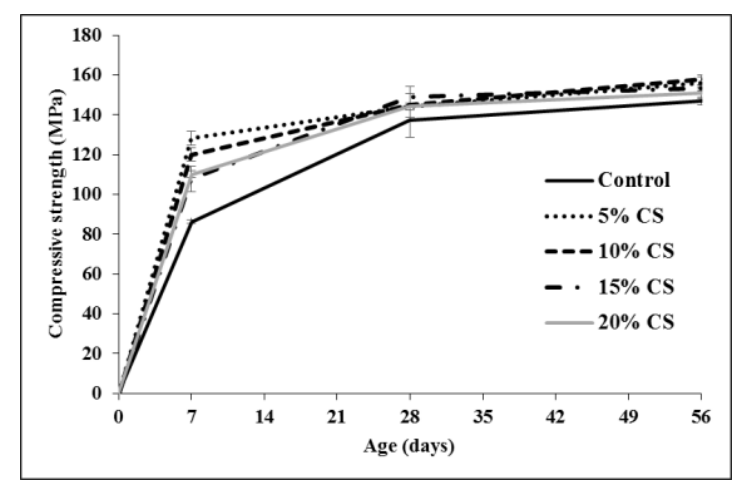

(b) Vacuum (100 mbar)

Figure 4. Compressive Strength of RPC (error bars represent standard errors, the average values represent three replicates)

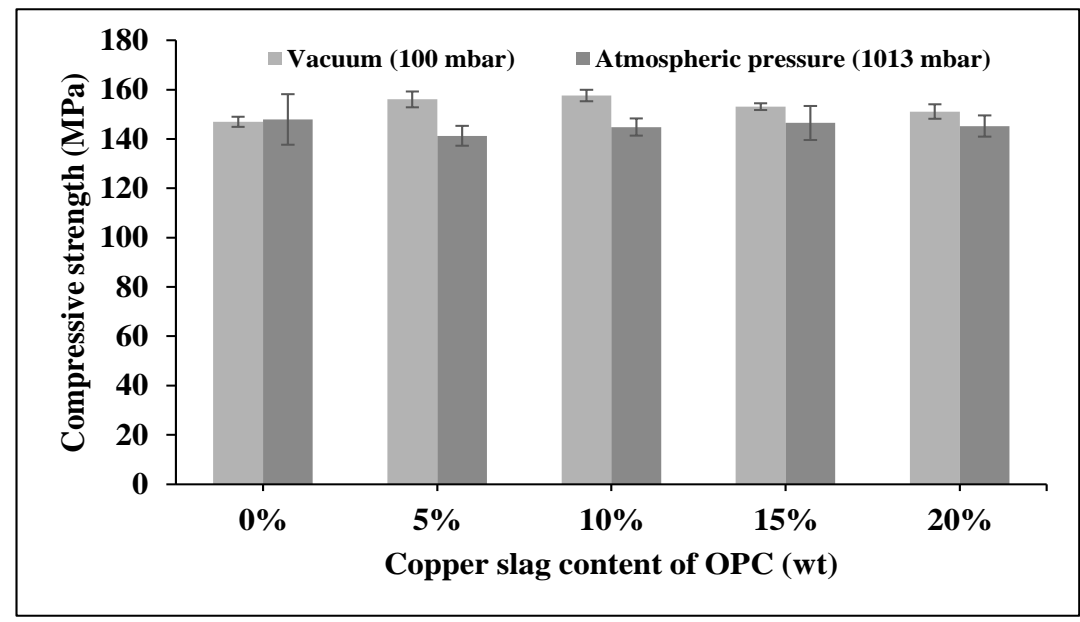

Figure 5. Strength of RPC mixed under Vacuum (100 mbar) and Atmospheric Pressure (1013) at 56 days (error bars represent standard errors, the average values represent three replicates)

The values of the density of hardened RPC mixed under vacuum condition and without vacuum are given in Figure 6. In general, the density of hardened RPC under vacuum condition (100 mbar) and RPC without vacuum (1013 mbar) slightly increased with rising copper slag content. Copper slag has a higher density, therefore a certain volume of cement is replaced by a smaller volume of copper slag. Thus the volume of binder (being the phase with the highest density) will decrease in the copper slag mixes. In the end, the volume of unreactive material (sand) will increase in the copper slag mixes to obtain $1 \mathrm{~m}^{3}$ of RPC. 
Figure 6 also shows that the density of hardened RPC under vacuum (100 mbar) is higher than RPC at atmospheric pressure (1013 mbar) for all series. This confirms that the higher strength of concrete depends on the density, which corresponds in this research for the higher compressive strength and density of RPC mixed under vacuum (100 mbar).

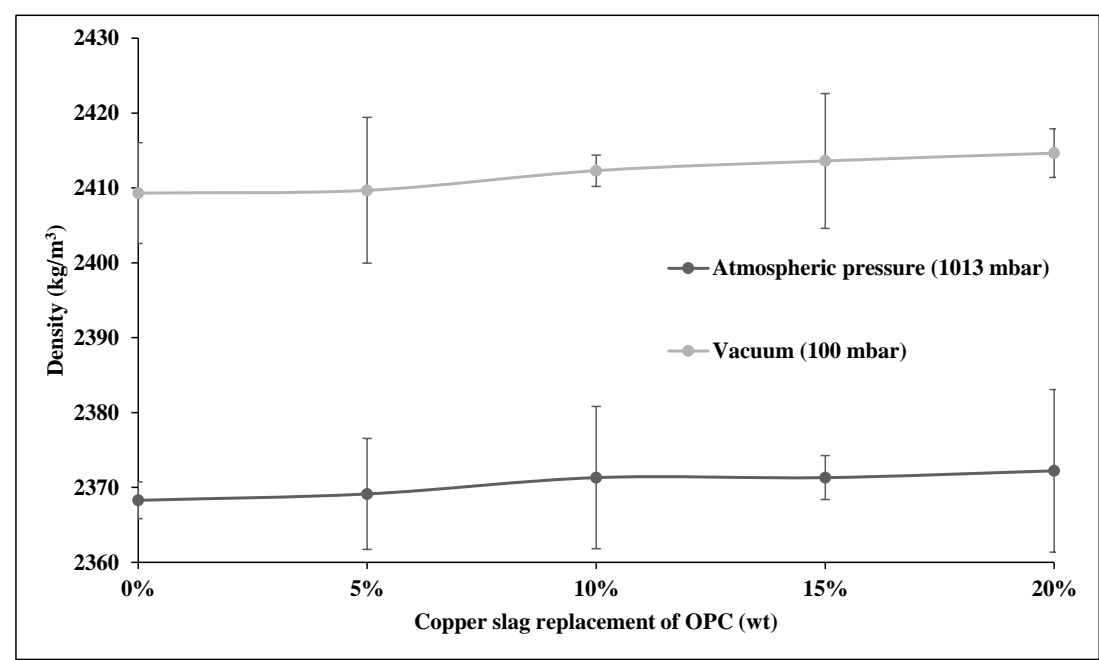

Figure 6. Density of Hardened RPC mixed under Vacuum (100 mbar) and Atmospheric Pressure (1013 mbar) (error bars represent standard errors, the average values represent three replicates)

Pozzolanic activity. Figure 7 shows the results obtained from the Frattini test. It is clear from the graph that the plotted data for 8 days curing were lying on or above the lime saturation isotherm, indicating that there is no reactivity. The amount of ca ion locates in the portlandite zone. For longer curing periods (i.e. 15 days at $40{ }^{\circ} \mathrm{C}$ ), all of the plotted data are located underneath the saturation curve of lime, indicating pozzolanic activity.

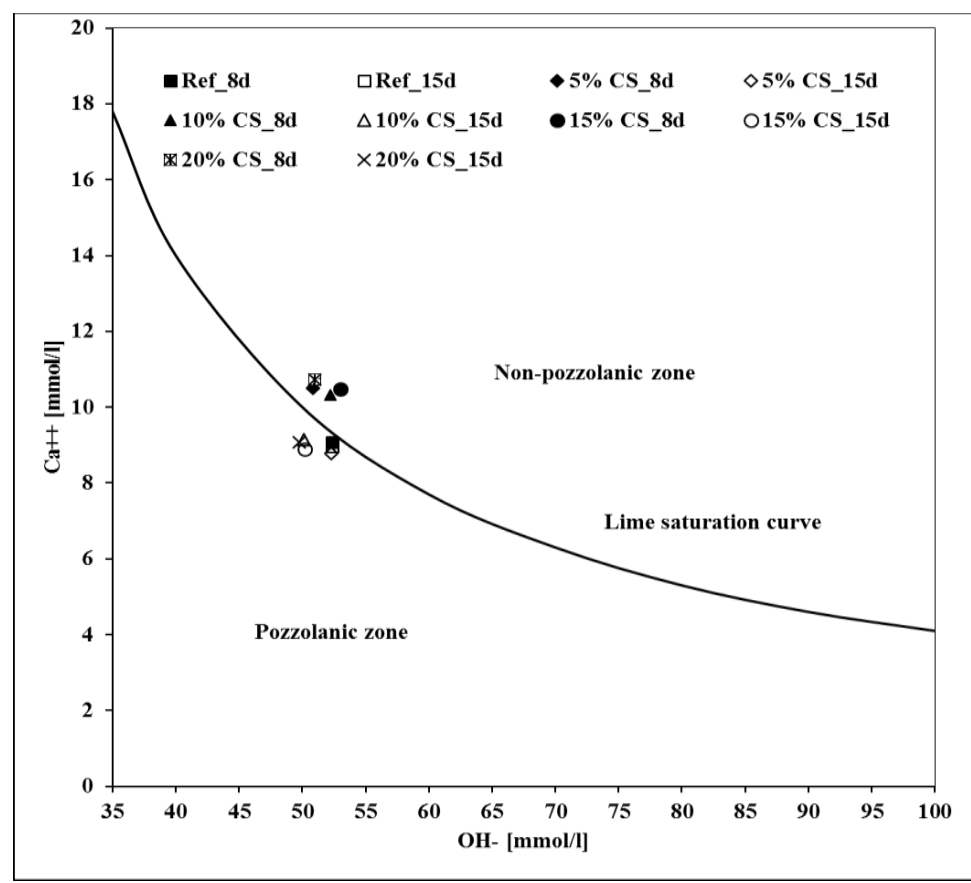

Figure 7. Frattini Test Result of Copper Slag at 8 Days and 15 Days 
Scanning electron microscopy (SEM). To investigate the influence of vacuum mixing on the porosity, scanning electron microscopy was performed on RPC samples. After performing compressive strength tests on RPC at 56 days, the broken specimens were impregnated (under vacuum) with epoxy and polished. Afterwards, the samples were investigated using a backscattered electron (BSE) detector with a constant magnification of 350x. In order to analyze the porosity on the obtained images by BSE, Matlab software was used. The capillary pore was chosen as a threshold in the phase segmentation. This software can detect and count the total porosity and the number of pores based on the grey levels of pixels.

Figure 8 describes the ratio of the total porosities and the number of pores for a RPC mixed under atmospheric pressure over a RPC mixed under vacuum. It is seen that the pore area of RPC mixed under atmospheric pressure is higher than that of RPC mixed under vacuum. For the reference, the ratio of pore areas reached $22 \%$, which means that a vacuum technique decreases significantly the total porosity of RPC. In the case of RPC with copper slag, using the vacuum technique reduces the pore area as the ratio of total porosity is more than 1 as can be seen in Figure 8. However, this effect is not statistically significant for these mixtures.

Figure 8 also gives the ratio of the number of pores of a RPC mixed under atmospheric pressure on the number of pores of a RPC mixed under vacuum. The highest ratio is achieved for the reference. In this case, the number of pores decreases significantly by applying the vacuum technique to the reference RPC mixture. In contrast to the reference, the number of pores of RPC under vacuum is higher than for RPC mixed under atmospheric pressure (except for the 5\% copper slag content) and the difference increases with rising copper slag content. It can be noticed that even though the effect of the vacuum technique is nihil to reduce the number of pores of RPC with copper slag, the larger air cavities can be minimized by using this technique.

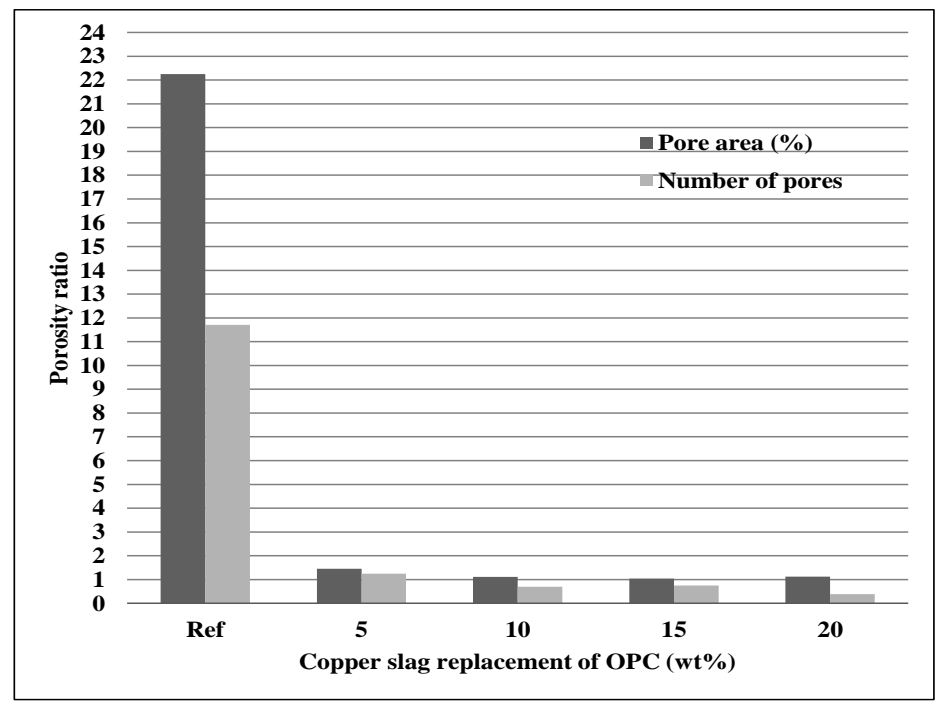

\section{Figure 8. Porosity Ratio of RPC mixed without Vacuum (1013 mbar) and RPC mixed under Vacuum (100 mbar) at Different Percentages of Copper Slag}

\section{CONCLUSION}

Within this paper the influence of intensive vacuum mixing on the compressive strength of RPC containing secondary slag as cementitious material was investigated. The following conclusions can be made:

1. There was a decrease in the workability of RPC mixed under vacuum conditions compared to the workability of RPC under atmospheric conditions although the workability increased gradually with rising copper slag content. 
2. By applying vacuum mixing to RPC mixture, both the compressive strength and the density increased. The presence of copper slag in the RPC mixture had an adverse effect on the strength for RPC without vacuum.

3. A significant decrease of the total porosity was achieved by using the vacuum technique, which had a positive effect on the compressive strength of the RPC.

4. The copper slag used in this study showed pozzolanic activity according to the Frattini test after curing 15 days at a constant temperature of $\pm 40{ }^{\circ} \mathrm{C}$.

\section{ACKNOWLEDGEMENTS}

The author would like to thank the Indonesian Government Scholarship (DIKTI) for providing the financial support to the $\mathrm{PhD}$ research project (2013-2016). Special thanks are addressed to the Magnel Laboratory for Concrete Research of Ghent University (staff and researchers) for their contribution to this research.

\section{REFERENCES}

Association, F.C. (2012). "Advance Recycling, From steel slag and $\mathrm{CO}_{2}$ to high-grade building materials". Interview Recmix Belgium, Metallo Chimique, CHAP-YT bvba, Umicore, D. Fransaer, Editor, FCA: Belgium.

Dils, J., Boel, V., and De Schutter, G. (2013). "Influence of Cement Type and Mixing Pressure on Air Content, Rheology and Mechanical Properties of UHPC". Construction and Building Materials, 41, 455-463.

Dils, J., Boel, V., and De Schutter, G. (2012). "Influence of Vacuum Mixing on the Microstructure of RPC". $3^{\text {rd }}$ International Conferene on the Durability of Concrete Structures, Queen's University, Belfast, September 17-19, 1-5.

Edwin, R. S., De Schepper, M., Gruyaert, E., and De Belie, N. (2015). "Effect of Copper Slag as Supplementary Cementitious Material (SCM) in Ultra-high Performance Mortar (UHPM)". International Conference on Concrete Sustainability, La Plata, Argentina, September 15-18, 11-21.

Ferarris, E. F. (2001). "Concrete Mixing Methods and Concrete Mixers: State of the Art”. Journal of Research of the National Institute of Standards and Technology, 106 (2), 391-399.

Gorai, B., Jana, R. K., and Premchand, 2003. "Characteristics and utilisation of copper slag - a review". Resources Conservation and Recycling, 39(4), 299-313.

Hagelüken, C., (2006). "Recycling of electronic scrap at Umicore precious metals refining". Acta Metallurgica Slovaca, 111-120.

Mazanec, O., and Schiessl, P. (2008). "Improvement of UHPC Properties Through an Optimized Mixing Procedure". $8^{\text {th }}$ International Symposium in Utilization of High-Strength and High Performance Concrete, Tokyo, Japan, October 27-29, 307-313.

Richard, P., and Cheyrezy, M. (1995). "Composition of reactive powder concretes". Cement and Concrete Research, 25(7), 1501-1511

Wille, K., Naaman, A. E., and. Parra-Montesinos, G. J. (2011). "Ultra-High Performance Concrete with Compressive Strength Exceeding $150 \mathrm{MPa}(22 \mathrm{ksi})$ : A Simpler Way”. ACI Materials Journal, 108(1), 46-54.

Yazici, H., Deniz, E., and Baradan, B.(2013). "The effect of autoclave pressure, temperature and duration time on mechanical properties of reactive powder concrete". Construction and Building Materials, 42, 53-63. 
Yu, R., Spiesz, P. and Brouwers, H. J. H.(2014). "Development of an eco-friendly Ultra-High Performance Concrete (UHPC) with efficient cement and mineral admixtures uses". Cement and Concrete Composites, 55, 383-394.

Zain, M. F. M., Safiuddin, M., Yusof, K. M. (1999). "A Study on the Properties of Freshly Mixed High Performance Concrete". Cement and Concrete Research, 29(9), 1427-1432.

Zenati, A., Arroudj, K., Lanez, M. and Oudjit, M. N.(2009). "Influence of cementitious additions on rheological and mechanical properties of reactive powder concretes". Physics procedia, 2(3), 12551261.

Zhang, Y., Sun, W., Liu, S., Jiao, C. and Lai, J.(2008). "Preparation of C200 green reactive powder concrete and its static-dynamic behaviors". Cement and Concrete Composites, 30(9), 831-838. 